\title{
DESENVOLVIMENTO LOCAL, REFORMA AGRÁRIA E OCUPAÇÃO TERRITORIAL: O CASO DO ASSENTAMENTO SÃO DOMINGOS DOS OLHOS D'ÁGUA
}

\author{
LOCAL DEVELOPMENT, LAND REFORM AND LAND \\ OCCUPATION: THE CASE OF THE SETTLEMENT SÃO \\ DOMINGOS DOS OLHOS D'AGUA
}

\author{
Moacir José dos Santos \\ Doutor em História. Docente e pesquisador do Mestrado em Planejamento e \\ Desenvolvimento Regional da Universidade de Taubaté (UNITAU) \\ Professor do Centro Universitário Módulo, Caraguatatuba/SP \\ professormoacirsantos@gmail.com
}

Alzair Eduardo Pontes

Mestre em Planejamento e Desenvolvimento Regional (UNITAU). Docente da Faculdade de Filosofia e Ciências Humanas de Goiatuba/GO alzairpontes@hotmail.com

\begin{abstract}
Resumo
O território constitui-se a partir das disputas sociais e políticas que o configuram. $\mathrm{O}$ objetivo da pesquisa é compreender as relações de poder relacionadas à ocupação e formação do Assentamento São Domingos dos Olhos D'água, localizado em Morrinhos/GO. O artigo resulta de uma pesquisa descritiva, da modalidade estudo de caso quanto à natureza das variáveis, associada a uma abordagem metodológica qualitativa, com dados descritivos pertinentes à realidade contextualizada. Identificou-se a presença de forças antagônicas no processo de ocupação e territorialização do espaço rural. Com suas associações e cooperativas, os assentados podem favorecer a promoção do dinamismo econômico e a melhoria da qualidade de vida de seus membros e da localidade de sua inserção. Contudo, esse processo é perpassado por conflitos relativos à estruturação do assentamento e da relação constituída com a comunidade externa. Conclui-se que o assentamento investigado é um espaço social complexo, marcado por disputas políticas em que grupos se interpelam na busca por organizar o território ocupado com práticas sociais e estratégias de luta oriundas dos interesses distintos dos sujeitos sociais participantes do processo de ocupação.
\end{abstract}

Palavras-chave: Desenvolvimento local. Reforma agrária. Ocupação territorial.

\begin{abstract}
The main objective of the research is to understand the power relations related to the occupation and settlement formation of São Domingos dos Olhos D'Agua. The article results from a descriptive research, characterized as a case study method according to the nature of the variables associated with it, with a qualitative approach, because the study was conducted in the settlement, with descriptive data related to the studied reality. The research revealed that there are opposing forces in the occupation of rural areas and territorial process. With their associations and cooperatives settlers may favor the promotion of economic vitality and improve the quality of life of its members
\end{abstract}

CAMPO-TERRITÓRIO: revista de geografia agrária, v. 11, n. 22, p. 311-340, abr., 2016 
and the insertion of its locality. However, this process is permeated by conflicts related to the structure of the settlement and by the relationship established with the external community. We conclude that the investigated settlement is a complex social space marked by political groups in which disputes in which groups interpellate themselves in the search for organizing the occupied territory with social practices and strategies of struggle coming from the different interests of the social actors participants of the occupation process.

Keywords: Local Development. Agrarian reform. Territorial occupation.

\section{Introdução}

O presente artigo realiza uma reflexão e o debate sobre a complexidade característica dos movimentos sociais relacionados aos conflitos no campo, especialmente quanto à territorialização das reivindicações pertinentes à reforma agrária e à consolidação dos assentados. Essas lutas ocorrem em um quadro marcado por relações de poder que, para Souza (1995), são geradoras de território, e o poder, de acordo com Raffestin (1993, p. 58), "visa o controle e a dominação sobre os homens e sobre as coisas", logo, sobre a população e sobre os recursos naturais. O domínio, o controle e a apropriação são materializados na transformação territorial.

Como a territorialização é o resultado da relação entre o domínio e a apropriação simbólica dos espaços em diferentes escalas pelas diversas classes sociais, podem formar-se diferentes territorialidades ao mesmo tempo. Para Haesbaert (2004), o território é o produto de uma relação desigual de forças, envolvendo o domínio ou controle político-econômico do espaço e sua apropriação simbólica, ora conjugados e mutuamente reforçados, ora desconectados e contraditoriamente articulados. Essa relação apresenta diversas variáveis, dependendo das classes sociais, dos grupos culturais e das escalas geográficas, relacionados à territorialização da luta pela terra. Sob essa perspectiva, delineiam-se múltiplos territórios, perpassados por múltiplas escalas de poder. Os conflitos agrários no Brasil configuram-se como embates que envolvem conflitos materializados no território, local de disputa entre aqueles que resistem à reforma agrária e os sujeitos sociais que buscam efetivá-la em um processo que envolve resistência, apropriação e permanência na terra. Destaca-se que a territorialização da reforma agrária não se esgota com a ação institucional de se efetivar assentamentos, mas continua na luta dos trabalhadores rurais para viabilizar sua conquista e demonstrar social, política e economicamente sua viabilidade. 
No contexto da política agrária brasileira, este estudo tem como referencial norteador a compreensão do território como o espaço onde o poder e a dominação articulam as condições definidoras da luta pela terra. É no território que se estabelece a relação desigual de forças que lutam pelo domínio e apropriação do espaço e seu controle político-econômico. A ocupação de uma fração do território é uma condição para os sujeitos sociais dedicados à reforma agrária, pois a viabiliza enquanto política pública resultante da organização dos trabalhadores rurais.

Para os movimentos sociais de luta pela terra, a ocupação é a condição da territorialização, pois, com a ocupação de uma parte do território, criam-se as condições políticas necessárias à luta por reforma agrária e políticas públicas correspondentes a sua viabilização. Para entender o processo de resistência, apropriação e permanência na terra, inerentes à territorialização da luta pela terra, investigou-se o Assentamento São Domingos dos Olhos D’Água, localizado ao sul do município de Morrinhos, no estado de Goiás. O objetivo é caracterizar os principais conflitos ocorridos no processo de ocupação, posse e permanência na terra pelos trabalhadores rurais do Projeto de Assentamento São Domingos dos Olhos D'Água.

A compreensão das relações de poder pertinentes à ocupação do território no contexto da reforma agrária em âmbito local é uma contribuição para a caracterização da sua territorialização e seus desdobramentos. As próximas seções caracterizam as referências conceituais utilizadas para organizar o método de pesquisa e a discussão dos resultados obtidos. Discute-se a relação entre desenvolvimento e territorialidade e também como ambas conectam-se à ocupação territorial enquanto estratégia de territorialização das demandas pertinentes à reforma agrária.

\section{Desenvolvimento local e reforma agrária}

O desenvolvimento de uma região ou localidade com o alcance de patamares melhores nos índices de qualidade de vida depende de políticas governamentais em todas as suas esferas; mas também, e principalmente, da iniciativa e da capacidade de mobilização conjunta dos movimentos sociais. Trata-se de coragem e vontade política e, em última análise, de deliberação e ação. Entende-se que o desenvolvimento é distinto do crescimento econômico, pois implica superação das assimetrias sociais e econômicas que reproduzem os processos de exclusão social (VIEIRA; SANTOS, 2013). 
A discussão sobre os fatores relacionados ao desenvolvimento mobiliza o debate contemporâneo centrado no exame das políticas públicas a ele dedicadas e nas suas consequências. A diversidade das avaliações sobre o desenvolvimento inclui alguns aspectos incontroversos entre os pesquisadores dedicados a sua investigação. Por exemplo, quando Amartya Sen (2000) ressalta o antagonismo entre a perspectiva voltada para as liberdades humanas em relação àquela que identifica desenvolvimento enquanto simples vetor de crescimento do Produto Nacional Bruto (PNB), destaca a necessidade de problematizá-lo como correlacionado a outros critérios que incluem equidade social e oportunidade de realização das aspirações pessoais. Para Sen (2000), há diversos elementos de privação de liberdade que são fontes inibidoras do desenvolvimento, entre eles, pobreza econômica, carência de serviços públicos e assistência social, negação de liberdades políticas e civis por regimes autoritários e de restrições impostas à liberdade de participação da vida social, política e econômica da comunidade. Segundo a perspectiva de Sen (2000), o desenvolvimento de um país estaria diretamente ligado às oportunidades que oferece à população de fazer escolhas e exercer sua cidadania, garantindo, tanto os direitos sociais básicos, como saúde e educação, como outros itens, tais como segurança, habitação, cultura e lazer.

Vieira e Santos (2012) afirmam que o entendimento da significação do conceito de desenvolvimento considera os valores históricos que foram construídos no decorrer do tempo em cada sociedade, apesar de conservar em seu âmbito a obtenção de padrões de vida superiores, acessíveis à população. Desse ponto de vista, o entendimento a respeito de desenvolvimento pode ser contrário ao conceito de progresso econômico, até porque seu objetivo vai além da oferta de bens e serviços provenientes do incremento de produtividade. Para Vieira e Santos (2012) e Vaz (2005), o volume de dinheiro ou bens materiais que promova o incremento da produção e da produtividade é relevante para o desenvolvimento econômico, contudo, uma distribuição mais justa dos recursos favorece a conciliação do desenvolvimento e a melhoria da qualidade de vida. Esse fenômeno pode ser definido como produtividade social, porque diz respeito à qualidade e quantidade da produção de bens e serviços realizada por uma dada comunidade, considerando um período de tempo. É capaz, ainda, de determinar como os bens e serviços produzidos favorecem o bem-estar da coletividade e de que maneira são divididos entre seus membros. Diante disso, a implantação das condições de desenvolvimento em âmbito local 
é viável e desejável, mesmo sendo de difícil entendimento em uma estratégia de médio prazo, com suporte tecnopolítico mais próximo. Deve-se levar em conta, também, o conceito de local, compreendido como território, que é definido a partir dos estudos referenciais, virtualidades e desafios que a comunidade exprime.

Veiga (2002) questiona a forma ortodoxa de desenvolvimento enquanto sinônimo de crescimento do Produto Interno Bruto (PIB), aumento da renda per capita, industrialização, avanço tecnológico ou modernização, apesar de também entender que esses elementos são basilares enquanto meios de expandir a liberdade. $\mathrm{O}$ autor destaca que o crescimento econômico estará na base do combate à pobreza, que dependeria, porém, de fatores como acesso a terra, educação, combate às discriminações étnicas ou de gênero, condicionantes fundamentais para a redução da pobreza.

Um aspecto a ser destacado refere-se ao fato de que a prevalência do entendimento do termo desenvolvimento, enquanto sinônimo de crescimento econômico, vem sendo relativizado desde o pós Segunda Guerra Mundial (1939-1945), tanto por pesquisadores, quanto por órgãos oficiais, tais como a Organização das Nações Unidas para a Agricultura e Alimentação (FAO), Programa das Nações Unidas para o Desenvolvimento (PNUD), Comissão Econômica para a América Latina e o Caribe (CEPAL), Banco Interamericano de Desenvolvimento (BID) e Banco Internacional para a Reconstrução e Desenvolvimento (BIRD), entre outros, de forma que essa concepção não é referência para as pesquisas sobre desenvolvimento ou para a elaboração de ações institucionais dedicadas ao combate à pobreza e à desigualdade. Por exemplo, o PNUD, agência de desenvolvimento da Organização das Nações Unidas (ONU), passou a conceber o ser humano como elemento central no debate sobre o desenvolvimento a partir da sua instalação, em 1965, bem como nas políticas socioeconômicas destinadas a melhorar as condições de vida da população. Nessa perspectiva, o fator humano passou a ser o elemento principal de progresso, e o desenvolvimento humano, o ponto focal do conceito de desenvolvimento (BUARQUE; BEZERRA, 1994).

Para Buarque e Bezerra (1994), o desenvolvimento local resulta de um ciclo virtuoso entre pequenas unidades territoriais e agrupamentos humanos que fomentam o dinamismo econômico e a melhoria da qualidade de vida de seus membros. Representa uma singular transformação na matriz econômica e na teia social em determinado local, resultante da mobilização de uma força motriz advinda da sociedade, pois os sujeitos 
sociais exercem suas capacidades e potencialidades específicas. Esse desenvolvimento pode alavancar as oportunidades sociais e viabilizar a competitividade da economia local, com potencial aumento da renda e das formas de riqueza, ao mesmo tempo em que assegura a conservação dos recursos naturais para que o processo se torne consistente e sustentável.

Apesar de constituir um movimento de forte conteúdo endógeno, o desenvolvimento local se insere em uma realidade mais ampla e complexa, com a qual cria interface e da qual recebe contribuições e pressões. O desenvolvimento local está associado, portanto, a processos mobilizadores da coletividade, articulando as potencialidades locais nas condições encontradas no contexto. As experiências de sucesso pertinentes ao desenvolvimento endógeno derivam frequentemente de um conjunto de fatores políticos e sociais favoráveis, incentivado por uma mobilização e, principalmente, união de propósitos dos atores sociais do município ou de determinada localidade em torno de prioridades e orientações básicas de desenvolvimento. Representa, nesse sentido, a associação dos atores que dão norte à viabilidade política a iniciativas e ações capazes de organizar as estratégias e promover a dinamização e transformação da realidade (CASTELS; BORJA, 1996).

O desenvolvimento de assentamentos da reforma agrária também é uma forma particular de desenvolvimento local delimitado pelo espaço da comunidade vinculado a projetos de assentamentos (AMORIM; VIEIRA; SANTOS, 2014). A reforma agrária no Brasil é um recurso para potencializar o desenvolvimento local, o que implica, contudo, na necessidade de investigação para orientar as políticas públicas com a produção do conhecimento pertinente à identificação das possibilidades correlacionadas a sua efetivação (MAIA; KHAN; SOUSA, 2013). A capacidade de organização comunitária necessária à viabilização dos assentamentos da reforma agrária enquanto vetor de desenvolvimento local está condicionada às condições de sua instalação e consolidação, o que implica a necessária produção de subsídios aptos a orientar as políticas públicas de desenvolvimento agrário e amparo aos assentados.

O impacto territorial existente no contexto dos assentamentos evidencia que se trata de uma construção resultante do encontro entre sociedade e espaço. O território se constitui enquanto tal, não porque é construído pelo homem apenas, mas porque tem um conteúdo político que passa pelas manifestações de poder sobre o espaço, sintetizando o 
conflito de classes existente na sociedade. Trata-se de impactos territoriais, porque as transformações no espaço, com as lutas e conquista da gleba de terra implicam alterações na relação de poder, conferindo ao território do assentamento um conteúdo essencialmente político e propício ao desenvolvimento. Um importante indicativo do desenvolvimento ocorrido em áreas de assentamento é a formação de grupos, cooperativas, associações, relações coletivas e comunitárias, entre outros. Na construção do território camponês, um conjunto de atividades coletivas é desenvolvido nos assentamentos a partir de espaços de socialização política.

A ideia de espaço de socialização política foi aplicada por Fernandes (1996). Para esse autor, existe uma multidimensionalidade no espaço de socialização política que se expressa nos diferentes espaços: comunicativo, interativo e de luta e resistência. A construção desses espaços é utilizada para compreender o desenvolvimento de ações coletivas pelos camponeses no interior dos assentamentos de trabalhadores sem terra. Para Furtado e Furtado (2000), os assentamentos são modelos de novos domínios da terra, resultados de políticas públicas que buscam mais justiça social com a redistribuição de terras, cujos envolvidos são os trabalhadores rurais sem terra. $\mathrm{O}$ termo assentamento, introduzido pelos órgãos oficiais, remete à ideia de alocação, de fixação dos trabalhadores na agricultura, daí o surgimento de uma nova categoria no meio rural: o assentado. Porém, as condições de instalação dos assentamentos remetem a uma realidade mais ampla e irredutível: a definição adotada por órgãos oficiais.

Os assentamentos assumem, então, configurações distintas coletivos/individuais; agrícolas/pluriativos; habitações em lotes/em agrovilas; frutos de programas governamentais estaduais/ federais; com poucas/muitas famílias; organizados e/ou politicamente representados por associações de assentados, cooperativas, movimentos sociais, religiosos, sindicais, etc. -, mas significarão sempre, malgrado as precariedades que ainda caracterizam número expressivo de projetos, um ponto de chegada e um ponto de partida na trajetória das famílias beneficiadas/ assentadas (LEITE, 2012).

A terminologia oculta uma ação anterior dos trabalhadores que lutaram pelo direito a terra. Esses meeiros, arrendatários, boias-frias, posseiros, ou pequenos proprietários, que foram expropriados de suas terras, há muito estavam esquecidos pelo sistema dominante, mas, aos poucos, conseguem o reassentamento. Não são tratados como sujeitos do processo e, sim, beneficiários de um programa governamental, o que oblitera a luta pelo acesso a terra. 
No início dos anos de 1980, intensificaram-se, em todo o Brasil, os movimentos sociais que reivindicavam a redemocratização do País e a melhoria das condições de vida dos trabalhadores na cidade e, principalmente, no campo, onde os conflitos por terra ganhavam visibilidade nacional. Como tentativa de intervir nesses conflitos, o Governo Federal estabeleceu o Plano Nacional de Reforma Agrária (PNRA) e criou o Ministério da Reforma e Desenvolvimento Agrário (MIRAD), como tentativa de diminuir os conflitos agrários a partir de uma ambiciosa distribuição de terras. Para o período de 1985 a 1989, foi previsto o assentamento de 1,4 milhão de famílias em todo território nacional (BRASIL, 2013).

No estado de Goiás que, na época, incluía o território do atual estado do Tocantins, a meta era assentar 125.500 famílias. Em 1986, o Plano Regional de Reforma Agrária de Goiás (PRRA-GO) reiterou essas previsões e ainda ressaltava que o Estado era considerado uma área prioritária para reforma agrária em razão do crescimento dos conflitos sociais. Segundo dados do Instituto Nacional de Colonização e Reforma Agrária (INCRA), no período de vigência do PNRA, de 1985 a 1989, registrou-se o assentamento de 775 famílias no estado de Goiás e 2.664 no estado do Tocantins, totalizando 3.439 famílias. Dados publicados pela Comissão Pastoral da Terra (CPT, 2011) registram que, em agosto de 2011, existiam 287 assentamentos criados e 14.750 famílias de trabalhadores rurais assentadas pelo INCRA no estado de Goiás.

Há uma diferença significativa entre as metas enunciadas e o que efetivamente foi alcançado no período. Entre a meta de 125.500 famílias e aquelas realmente assentadas, há um hiato de 110.750 famílias não assentadas. Depreende-se a ausência de um comprometimento mais efetivo com a reforma agrária e os possíveis benefícios gerados por sua consecução, especialmente para a indução de processos de desenvolvimento local. Ressalta-se que o desenvolvimento de uma localidade correlaciona-se com a formação do capital humano, econômico e social constituído por ações realizadas e relações entre indivíduos, governos, organizações representativas e sociedade civil. A agricultura familiar, principalmente a desenvolvida nos assentamentos rurais, insere-se nesse contexto por meio de associações e cooperativas agrícolas familiares.

Ilações sobre desenvolvimento regional e inclusão social estão presentes nas discussões e agendas de governos que, preocupados com a reversão de indicadores 
como concentração de renda, desemprego, fatores ambientais, êxodo rural e concentração urbana, vêm disseminando e fomentando políticas públicas voltadas para o desenvolvimento local. Porém, a efetivação do desenvolvimento regional e local implica uma opção política quanto aos instrumentos e resultados. A elevação da qualidade de vida da população depende de ações correlacionadas à inclusão produtiva e ao empoderamento político necessários para o rompimento com um modelo de relações políticas pautadas na passividade e subordinação dos cidadãos, característico das relações sociais, econômicas e políticas correlacionadas ao capital financeiro condutor da globalização. O desenvolvimento regional e local constitui estratégia para o rompimento com os mecanismos reprodutores da exclusão econômica, social e política, desde que se constitua enquanto alternativa distinta das formas de adesão ao capital financeiro internacional, condutor da contemporânea divisão internacional do trabalho.

As barreiras para o desenvolvimento de setores excluídos da população, ou melhor, incluídos de maneira periférica, demonstram os equívocos da sociedade consumista como exemplo de desenvolvimento global, criando possibilidades de opções epistemológicas e inovadoras do ponto de vista social. A sistemática exclusão social, econômica e política observada em diversas regiões do mundo evidencia os limites da globalização e o equívoco de referenciá-la como modelo para o desenvolvimento global, especialmente por desconsiderar as características e condições peculiares de cada população e região do globo. Sob essa perspectiva, Boaventura Santos e Meneses (2010) propõem a contestação da epistemologia predominante do século XIX em favor da diversidade, contraponto para a efetivação de formas de desenvolvimento inclusivas por contemplarem a multiplicidade das experiências humanas, especialmente para combate às atuais formas de exclusão. Para Arrighi (1997), o modelo de desenvolvimento contemporâneo pauta-se na existência do subdesenvolvimento para que possa se perpetuar. Os países desenvolvidos dependem das condições presentes nos países periféricos para a manutenção de sua posição hegemônica, de modo que são formados três mecanismos principais de manutenção do status quo: fortalecimento do capital, trocas desiguais e transferências unilaterais de mão de obra. A centralidade dos Estados Unidos e dos países da Europa Ocidental está associada à preservação de um modelo econômico apto a sustentar a concentração dos recursos necessários ao padrão socioeconômico das respectivas populações. O desenvolvimento dos Estados Unidos e dos países da Europa 
Ocidental não se correlaciona somente à competência econômica e às relações políticas presentes nessas sociedades, mas aos mecanismos pertinentes à externalização dos custos econômicos e sociais associados à extração de excedentes dos países periféricos.

As ações para efetivar o desenvolvimento local têm o potencial para produzir formas de resistência aos mecanismos de inclusão periférica apontados por Arrighi. Afinal, é no cotidiano social que se constituem as ações de resistência à concentração de renda e exclusão social. Entretanto, Costa et al. (2010) denotam que os trabalhadores rurais assentados, ao incorporarem-se em uma associação, não necessariamente mantêm uma perspectiva de ação coletiva, passando a ter sua representação centrada na satisfação dos interesses individuais, o que configura um distanciamento das condições necessárias ao sucesso social e econômico dos sujeitos beneficiados pela reforma agrária. Os autores apontam a possibilidade das associações sociais organizativas converterem-se em espaços de intenções individuais. Por exemplo, os autores discutem sobre a possibilidade de um líder comunitário em projetos de assentamentos rurais buscar o domínio sobre os demais assentados como mecanismo de afirmação de interesses pessoais.

Tal configuração pode favorecer o surgimento de líderes autoritários e centralizadores, dificultando a constituição de processos de desenvolvimento local pautados nas ações coletivas centradas no combate às assimetrias sociais. A reversão deste cenário implica a utilização de normas baseadas em relações de reciprocidade, auxiliando a formação associativa como indutora da prática de atitudes que fomentem o espírito de cooperação e de solidariedade, fatores propícios para o desenvolvimento local. O grau de empoderamento político coletivo aponta os caminhos do desenvolvimento local. De modo mais específico, pode-se afirmar que a participação coletiva conduz de modo mais seguro à redução das desigualdades sociais (PUTNAM, 2006).

Assim, nas sociedades em que o grau de politização e empoderamento da sociedade civil é elevado, tem-se maior força para o estabelecimento de mobilizações, para a liberalização de forças produtivas que visem pôr em prática um caminho para o desenvolvimento que tenha por escopo o bem-estar social. A premissa dessas afirmações baseia-se na existência de redes de relações formais e informais que, reconhecidas pela cooperação e reciprocidade entre seus atores, são elementos de fomento ao desenvolvimento. As pesquisas recentes sobre desenvolvimento demonstram que as práticas participativas são elementos balizadores dos processos de 
desenvolvimento regional (CARNIELLO; SANTOS, 2011). Os lugares e regiões que melhor conseguiriam desenvolver-se seriam aquelas que apresentariam maior articulação dos fatores endógenos, direcionando-os para o fortalecimento de uma teia social, para o aumento da autonomia local dos atores nas tomadas de decisão, para a capacidade de acumular e reinvestir capitais em nível local, enfim, para promover a inclusão social e o aumento da disposição de promover ações amigáveis em relação ao meio ambiente. Os projetos de assentamentos são modelos que, em tese, aproximam-se desse ideal de desenvolvimento desde que preservem a ação coletiva como vetor de organização e consolidação.

\section{Ocupação territorial}

Os espaços geográficos são objetos de demandas, conflitos e conquistas. Em cada período histórico expressam as características do sistema político e econômico dominante (SANTOS, 2007). Segundo Haesbaert (2004), com o surgimento de uma nova geografia, na década de 1970, novos espaços começaram a ser definidos e o território passou a ter uma significação mais ampla, deixando o conceito de ser simplesmente um espaço geográfico, um pedaço de solo.

Para Raffestin, o território é formado pelas relações sociais que se dão no espaço, o que difere da simples concepção de demarcação de espaço, portanto, para esse autor, o território só pode ser caracterizado como um espaço onde se articulam as relações de poder. Essas relações são estabelecidas pelo conflito entre as classes sociais que tentam apropriar-se de porções do espaço, entendido como uma espécie de matériaprima transformada em território pela ação dos atores sociais. Nesse sentido, a ocupação territorial surge como advento que determina o desenvolvimento e é percebido como espaço do poder, fundamentado em relações sociais que se pautam nos múltiplos poderes instituídos (RAFFESTIN, 1993).

Para Fernandes (1994), no ambiente globalizado, instalado a partir de 1980, o território ganhou novas definições, pois é reproduzido e organizado por relações sociais de classes e revela os movimentos de dominação e resistência. Fernandes afirma que essa dominação, balizada pelo modo de produção capitalista, não atende a quem tem a força de trabalho, mas sim ao capital, fomentando ainda mais as disparidades sociais 
resultantes de uma configuração econômica e social em que poucos acumulam e muitos são excluídos da apropriação da riqueza socialmente produzida.

Raffestin (1993) considera que o domínio de um território é mais do que uma simples relação homem-território. O autor ressalta que existem relações sociais entre os homens que vão além da demarcação de espaços geográficos. A ocupação territorial seria, então, "um conjunto de relações que se originam num sistema tridimensional compreendido por sociedade, espaço e tempo em vias de atingir a maior autonomia possível, compatível com os recursos do sistema" (RAFFESTIN, 1993, p. 160).

A ocupação e a exploração do espaço denotam o estado de organização das relações de produção, particularmente quanto à possibilidade de ordenar o território para reproduzir as condições necessárias à contínua expansão do capital. Carniello e Santos evidenciam a necessidade de perceber que o território e o espaço constituem-se em função da dinâmica histórica:

[...] a produção do espaço capitalista é histórica e geograficamente localizada, com a respectiva concentração da riqueza no que tange às dimensões espacial, social e funcional. [...] A expansão do capital depende de sua concentração espacial em determinada região ou país quanto à disponibilização dos recursos financeiros, materiais e tecnológicos necessários à elevação da riqueza, o que potencialmente dificulta sua circulação e o aumento do consumo. Deste modo, os períodos de bonança econômica correspondem ao crescimento da riqueza e à elevação do consumo em virtude da bem sucedida incorporação de mercados consumidores e trabalhadores submetidos à hierarquia espacial e funcional da atividade econômica, porém na medida em que cada ciclo atinge seus limites técnicos e econômicos advém a crise em função da redução da circulação do capital correspondente à obtenção do lucro almejado com o ciclo de produção e consumo (CARNIELLO; SANTOS, 2013, pp. 334-335).

Para Heidrich (1998), entre a ocupação e a materialização do habitat há características da condição territorial, como apropriação, domínio, identidade, pertencimento, demarcação e separação, que contribuem para uma completa efetivação do território. Nessa concepção, Raffestin (1993) ressalta que os territórios formados no espaço podem ser conquistados em favor de determinados grupos. O espaço do assentamento rural constitui-se como baluarte de determinadas relações, formando o território camponês. $\mathrm{O}$ assentamento é um espaço que promulga conteúdos históricos resultantes de processos políticos e sociais. Trata-se de um espaço onde se articulam as relações sociais, no caso, relações associadas à ocupação territorial rural. Nesse lócus as 
famílias assentadas constroem um território camponês percebido nas relações econômicas, políticas e sociais.

Para Fernandes (1998), a ocupação é uma espécie de territorialização materializada com o acampamento, evento que mobiliza os sem terra para a ocupação de um espaço geográfico. Nessa ótica, a ocupação é um embrião da construção de um território, pois, a partir da terra ocupada, afloram novos movimentos em um processo que se realiza no enfrentamento entre a territorialização das relações capitalistas e territorialização camponesa: é aquele espaço geográfico ocupado (fração de terra) que estabelece a territorialização e não a ocupação em si.

Segundo Haesbaert (2004), o território é um espaço onde o poder e a dominação predominam, pois é no território que surge uma relação desigual de forças que lutam pelo domínio e apropriação do espaço por meio do controle político-econômico. Santos (2002 p. 10) ainda afirma que: "O território é o fundamento do trabalho, o lugar da residência, das trocas materiais e espirituais e do exercício da vida".

Em relação a esse pressuposto de território, Santos (1996) esclarece que não deve ser adotada uma análise em um processo de desterritorialização, entendida aqui como exclusão de um número expressivo de pessoas que buscam alternativas de melhores condições de vida fora dos seus lugares de origem, fundada apenas em conjunturas cultural e política, mas também de forma conjunta aos processos econômicos, principalmente à dinâmica capitalista de apropriação do capital e de seus meios de produção. O território não pode ser entendido apenas como uma ocupação ou como entidade exterior aos que o habitam, pois é identidade, fonte de uma relação de essência afetiva ou mesmo amorosa com o espaço. É tido como a identidade daqueles que o ocuparam. Talvez a marca mais preponderante de território seja a simbiose entre as pessoas e o espaço de domínio (HAESBAERT, 2004).

O marco territorial, para Haesbaert (2004), deve ser analisado de forma integradora, levando em consideração a dimensão simbólica, cultural, material, econômica, política, social e histórica dos indivíduos ou do grupo social. Conforme o mesmo autor: "não há indivíduo ou grupo social sem território, quer dizer, sem relação de dominação e/ou apropriação do espaço, seja ela de caráter predominantemente material ou simbólico" (HAESBAERT, 2004, p. 239). 
A construção de um território provoca uma demarcação de fronteiras que leva a um controle determinado aos que estão dentro e fora dele. Toda relação de poder espacialmente mediada é também construtora de identidade, pois controla, distingue, separa e, ao separar, de alguma forma nomeia e classifica os indivíduos e os grupos sociais, tanto em momentos de conflitos como em negociações.

O assentamento é o território conquistado, é, portanto, um novo recurso na luta pela terra que significa parte das possíveis conquistas, e representa, sobretudo, a possibilidade da territorialização (FERNANDES, 1996, p. 181).

A utilização do conceito de território por distintos atores sociais caracteriza a luta pelo poder que envolve conflitos por definição de territórios. Das técnicas reveladoras de interesses dentro do campo de poder, submergem posições contrárias e convergentes (BOURDIEU, 2004).

\section{Método}

Trata-se de uma pesquisa descritiva, da modalidade estudo de caso quanto à natureza das variáveis, associada a uma abordagem metodológica qualitativa, pois o estudo se desenvolveu no Assentamento São Domingos dos Olhos D'Água, com dados descritivos pertinentes à realidade contextualizada. Nesse sentido, Richardson (1999) pontua que na pesquisa qualitativa há uma ausência de hipóteses rígidas, o que possibilita maior flexibilidade para formular ou reformular hipóteses à medida que se realiza a pesquisa.

No percurso metodológico desta investigação, optou-se por delinear uma direção segura conforme os padrões éticos e metodológicos da pesquisa qualitativa preconizada por Hernández Sampieri et al. (1991), pois, tanto para a análise documental, quanto no trato com pessoas, no tocante a questões éticas, foram obedecidos os pressupostos referentes ao desenvolvimento de projetos de pesquisa.

Pesquisaram-se, também, a origem dos trabalhadores rurais sem terra; as Instituições que coordenaram e apoiaram o movimento de ocupação e a organização na chegada ao acampamento; a forma de distribuição dos lotes pelo INCRA; a produção dos assentados; e as políticas públicas desenvolvidas no assentamento, entre outros.

Mais especificamente, para a opção metodológica adotada, a análise aconselhada por Bardin (1994) e Franco (2003) é a verbal, pois suas duas áreas, a oral e a escrita ${ }^{1}$, 
enquadram-se perfeitamente nos objetivos propostos, que visam compreender as relações de poder relacionadas à ocupação do território no contexto da reforma agrária em âmbito local, com o intuito de encontrar elementos manifestos ou pressupostos que permitam afirmar a existência de enfrentamentos na luta pela terra.

A análise preconizada por Bardin (1994) e Franco (2003) auxiliou na busca de elementos qualitativos relativos a palavras, temas e mensagens subjacentes ou manifestas nos documentos, com finalidade explícita e até mesmo de completar este estudo com elucidação da incidência e forma como os conflitos aparecem nos documentos.

A escolha de documentos para a análise foi embasada na proposta de Yin (2002), que observa como critérios:

- $1^{\circ}$ ) busca exaustiva de documentos: particularmente neste estudo, em razão da objetividade do projeto de pesquisa. A busca direcionou-se exclusivamente para os documentos norteadores da Cooperativa e na Associação de Agricultores; no assentamento; na Comissão Pastoral da Terra (CPT); no Instituto Nacional de Colonização e Reforma Agrária (INCRA); no Sindicato dos Trabalhadores Rurais de Morrinhos (STR) e no Cartório de Registro de Imóveis e Tabelionato da Comarca de Morrinhos;

- $2^{\circ}$ ) representatividade: foram selecionados apenas documentos oficiais como atas, registros cartorários, relatórios de órgãos governamentais; matérias publicadas em jornais e no boletim da CPT; e

- $3^{\circ}$ ) homogeneidade: foram solicitados e analisados, em todos os casos, os mesmos tipos de ocorrência.

Com intuito de sintetizar os procedimentos metodológicos utilizados no desenvolvimento deste trabalho, foi estruturado o Quadro 01: 
Quadro 01: Síntese dos procedimentos metodológicos adotados no estudo

\begin{tabular}{|c|c|}
\hline & Estudo de caso \\
Classificação da pesquisa & Exploratória \\
& Descritiva \\
& Qualitativa \\
\hline Ambiente da pesquisa & Pesquisa bibliográfica \\
& Pesquisa de campo \\
\hline Técnicas de coleta de dados & Pesquisa bibliográfica \\
& Pesquisa documental \\
& Entrevistas individuais \\
\hline Técnica de análise de dados & Análise interpretativa \\
\hline
\end{tabular}

Fonte: Pontes (2014).

O instrumento utilizado na pesquisa de campo foi aplicado por amostra censitária e permitiu ao pesquisador fazer uma leitura, por meio dos documentos oficiais e também dessas entrevistas, dos enfrentamentos ocorridos no processo de ocupação (1997), posse (2004) e permanência, até 2014, nos lotes de terra do assentamento estudado. Foi usada a fórmula de cálculo de amostra finita, conforme Richardson (1999). O número mínimo calculado previsto para aplicação dos questionários era de 60 entrevistados, no entanto foi alcançada a amostra de 72 questionários válidos.

\section{Ocupação territorial e desenvolvimento local}

O assentamento São Domingos dos Olhos D’Água, territorializado na antiga fazenda São Domingos dos Olhos D’Água, propriedade privada classificada como individual e improdutiva pelo INCRA (1997), dividida em 86 parcelas para as famílias ali assentadas, remete a uma forma de acesso a terra oposta à concentração da propriedade fundiária presente no país. Tal oposição decorre do acesso a terra e à inclusão produtiva possibilitada com a reforma agrária. O assentamento São Domingos dos Olhos D’Água é pejorativamente referência na região como lugar dos sem terra. A fazenda São Domingos dos Olhos D’Água fica no sudeste do município de Morrinhos (GO) e possui terras bastante valorizadas no mercado imobiliário. A fazenda tem extensas áreas com vegetação de cerrado preservadas, que se tornaram reservas legais, conforme Figura 1. Seu potencial hídrico é suficiente para atender aos assentados quanto à satisfação das suas necessidades básicas e para a produção realizada no assentamento: possui dois ribeirões, Lageado e São Domingos, e três córregos, Vai-Volta, Cabeluda e Candiúba (Figura 1). Cinco dos 86 lotes limitam-se com o Rio Meia Ponte. 
Figura 1: Mapa do loteamento do São Domingos dos Olhos D’Água, Município de Morrinhos (GO)

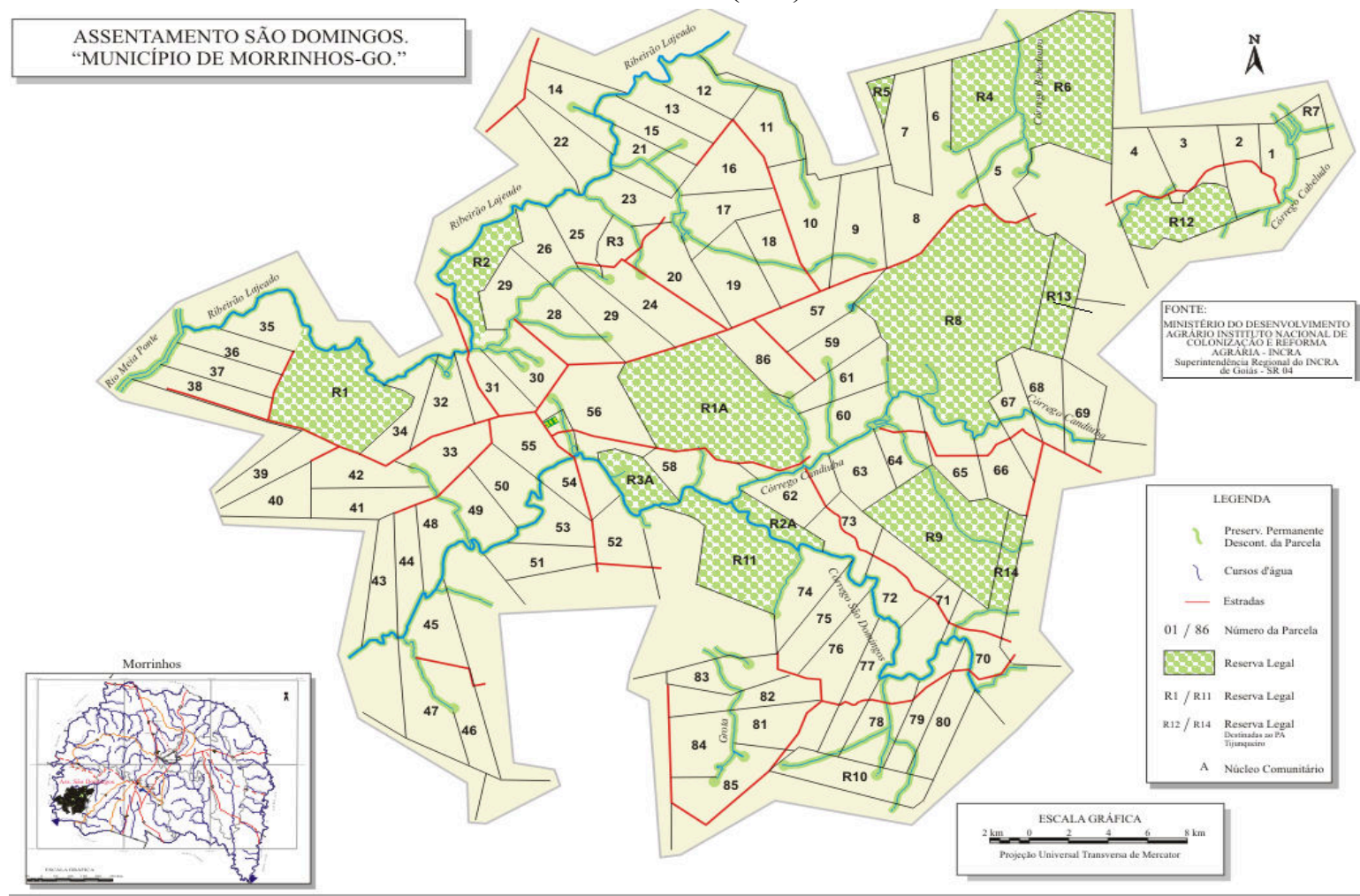

Fonte: Adaptado de Silva (2006).

Para compreender as formas de ocupação e organização socioespacial do objeto de pesquisa, o assentamento São Domingos dos Olhos D’Água, em Morrinhos (GO), foi necessário analisar o processo de luta pela terra com os vários sujeitos que dela participaram em diferentes estágios. São homens, mulheres e suas crianças que, imbuídos de sua herança cultural, resolvem lutar coletivamente para terem acesso a terra para trabalho. Pressionados nos centros urbanos, sem alternativa de sobrevivência, restou o retorno a terra com luta. Essas pessoas puderam contar com entidades que colaboraram, como mediadoras, com esse ideal, o que torna o processo coletivo e solidário (STEDILE, 2002).

O assentamento São Domingos dos Olhos D’Água surgiu do acampamento, na própria fazenda com o mesmo nome, de trabalhadores rurais sem terra que reivindicavam a sua posse por ter conhecimento que tramitava processo no INCRA, no qual a propriedade seria declarada improdutiva, não cumprindo a função social nos termos da Lei 8.629/93. O INCRA, após várias expedições técnicas in loco, constatou oficialmente que as terras eram improdutivas. A decisão do INCRA foi publicada em 09/10/1997, no 
Diário Oficial da União, e a fazenda São Domingos dos Olhos D'Água, município de Morrinhos, foi considerada de interesse social para fins de reforma agrária. A fazenda possuía 3.446,56 hectares e tinha como proprietário Lindolfo Gomes Ferreira.

Acamparam no local, em 1997, 85 famílias, e foram várias as fases de luta que vivenciaram para terem acesso a terra, o que fez com que se unissem desde o acampamento até à luta cotidiana para permanência na terra conquistada.

O assentamento foi criado pela Portaria n 09/98, de 22 de dezembro de 1997, do superintendente regional do INCRA do estado de Goiás. É uma gleba de terras inserida no meio de latifúndios monocultores exportadores, que utilizam tecnologia de ponta e produção em escala. Conta com 14 reservas ambientais permanentes, pois $20 \%$ da área total de uma propriedade rural têm que ser preservados, conforme o Decreto 6.514, que regulamenta a Lei de Crimes Ambientais. As reservas ambientais do assentamento são, segundo informações colhidas no INCRA, superiores aos $20 \%$ previstos em Lei, diferentemente das propriedades circunvizinhas, que desmataram matas ciliares e áreas de cerrado. Tal condição caracteriza a maioria das propriedades da agricultura capitalista em toda região sul do estado de Goiás.

Os lotes são de tamanhos diferentes e essa diferença se deve à qualidade do solo e ao relevo; lotes de solos mais férteis em relevo mais plano são menores, e lotes com solos menos férteis com relevos mais movimentados são maiores (Figura 1). De acordo com o Ministério do Desenvolvimento Agrário, Instituto Nacional de Colonização e Reforma Agrária (INCRA), Superintendência Regional do INCRA de Goiás, SR 04, Divisão Técnica, a área total do Assentamento é de 728,19 alqueires, ou seja, 3.448,56 hectares. A Reserva Legal do PA São Domingos dos Olhos D’Água é de 790,80 hectares; a Reserva Legal de outro assentamento, o Tijunqueiro, também se encontra dentro do assentamento São Domingos dos Olhos D’Água e é de 80,07 hectares. A Área de Preservação Permanente (APP) é de 62,37 hectares. Essas informações foram extraídas do Memorando No830/97/SR-Z. Protocolo de Criação do Assentamento São Domingos dos Olhos D'Água. Depreende-se, a partir destas informações, que são dedicados aos assentados 2515,32 hectares.

Ao analisar os dados coletados nas entrevistas realizadas no assentamento nos meses de dezembro de 2013, janeiro e fevereiro de 2014, verificou-se que o tempo de residência de $70 \%$ dos parceleiros ${ }^{2}$ no assentamento é, em sua maioria, o mesmo de 
existência do assentamento. Poucas unidades tiveram realocação após 2004, ano em que a terra foi finalmente desapropriada e entregue aos acampados remanescentes no local e aos demais trabalhadores rurais sem terra cadastrados no INCRA para serem assentados.

Entre os 72 entrevistados, todos titulares dos lotes, constatou-se que apenas 26 eram remanescentes das 85 famílias que ocuparam, pacificamente, a fazenda São Domingos dos Olhos D'Água em 1997, portanto, apenas 32\% conseguiram vencer os quase sete anos de acampamento. Outros 12 assentados só chegaram ao local mais recentemente, há menos de três anos, e também foram assentados pelo INCRA, ou ainda esperam pela regularização que está tramitando no Órgão, correspondentes a 16,66\%.

Gráfico 1: Tempo de fixação nas parcelas do PA São Domingos dos Olhos D'Água

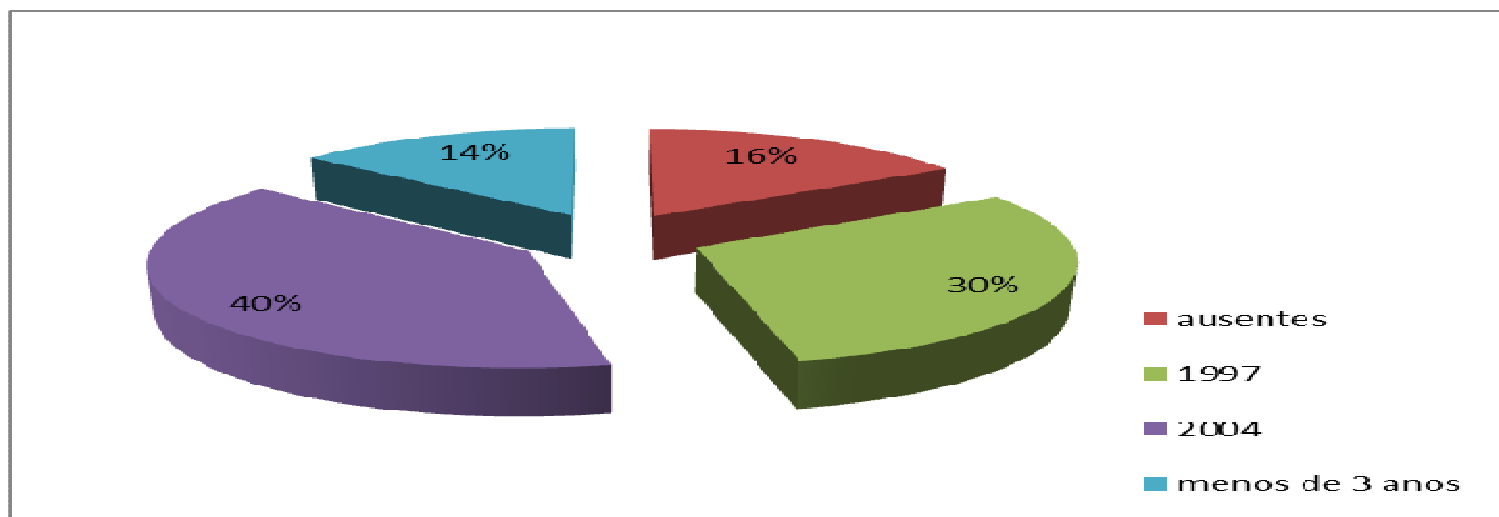

Fonte: Pontes (2014).

No primeiro momento, o objetivo foi alcançado, pois a pretensão era identificar o responsável pelo lote, bem como o tempo de posse. O Gráfico 1 demonstra que 30\% dos parceleiros entrevistados resistem no local desde a formação do acampamento, em 1997. Outros 40\% ingressaram no território somente no ato da regularização: foram capitaneados pelo INCRA e são oriundos de outros acampamentos ou dos cadastrados da entidade de outras regiões. Os substitutos daqueles que, por algum motivo desistiram, ou foi permitida a sua substituição pelo INCRA, como é o caso das pessoas que adoeceram e não tinham familiares para manusear o lote e torná-lo produtivo na forma exigida pelo INCRA, totalizam $14 \%$.

É salutar ressaltar que as famílias que não fizeram parte da luta na fase de acampamento foram selecionas pelo INCRA e submetidas à apreciação da Associação de Moradores do Assentamento São Domingos dos Olhos D'Água para, depois de aceitas, tomarem posse do lote disponível. 
Quando inquiridos sobre a ajuda dos movimentos sociais de luta pela terra para a conquista do lote, disseram que o Sindicato dos Trabalhadores Rurais de Morrinhos, a Federação dos Trabalhadores na Agricultura do Estado de Goiás (FETAEG) e a CPT foram imprescindíveis para a aglutinação das pessoas e pela permanência no acampamento. Essas entidades deram apoio moral e material e contribuíram para amenizar as dores e privações da fase de acampamento. Nessa questão, incluiu-se também o INCRA como órgão que muito ajudou na conquista. A participação efetiva e constante do órgão oficial da reforma agrária deu-se por causa da dificuldade que o INCRA teve para garantir efetivação da emissão de posse da propriedade, que foi objeto de batalha judicial recheada de ações cautelares, agravos, mandados de segurança.

Nas entrevistas, os assentados ressaltaram que tinham medo da pistolagem, porque no processo de ocupação capangas e capatazes incessantemente rondavam os três acampamentos distribuídos pela propriedade. Em pesquisa documental, constatouse que foram registradas várias denúncias formais e publicadas inúmeras notícias desses conflitos armados em jornais e informativos da CPT. Há, inclusive, registros nos anais da Câmara dos Deputados Federal, em discurso proferido pelo então deputado Aldo Arantes (PC do B-GO). Os poderes legalmente constituídos pouco fizeram no processo de ocupação e posse dos lotes, apenas o Poder Judiciário não se eximiu de, a seu tempo, sentenciar os processos relacionados aos assentamentos.

Essa realidade corrobora a perspectiva de Oliveira (1997), que afirma que a política latifundiária implementada no país durante décadas atendia ao capital e levava à concentração de terras, ao aumento da violência no campo, à miséria dos trabalhadores rurais, à expulsão dos chamados camponeses de suas terras, e à perspectiva da não realização de uma reforma agrária que equacionasse a questão da terra no País.

A observação dos dados possibilitou verificar que, antes de acampar, grande parte dos assentados estava desempregada ou trabalhava de forma autônoma como prestadores de serviços não especializados; uma pequena minoria era de empregados em fazendas localizadas em Morrinhos (GO) ou em outras localidades. Essa população foi expulsa do campo pela tecnificação, pois o capital, ao reestruturar a produção no campo, não absorveu a mão de obra dos camponeses, e uma das alternativas que lhes restou foi buscar os centros urbanos como via de sobrevivência.

Ao verificar a origem da última residência dos 72 assentados do PA São 
Domingos dos Olhos D'Água, entrevistados em janeiro e fevereiro de 2014, os dados apontam que metade dos assentados tem origem no sul goiano, conforme o Gráfico 2.

Gráfico 2 - Assentamento São Domingos dos Olhos D’Água: origem dos assentados

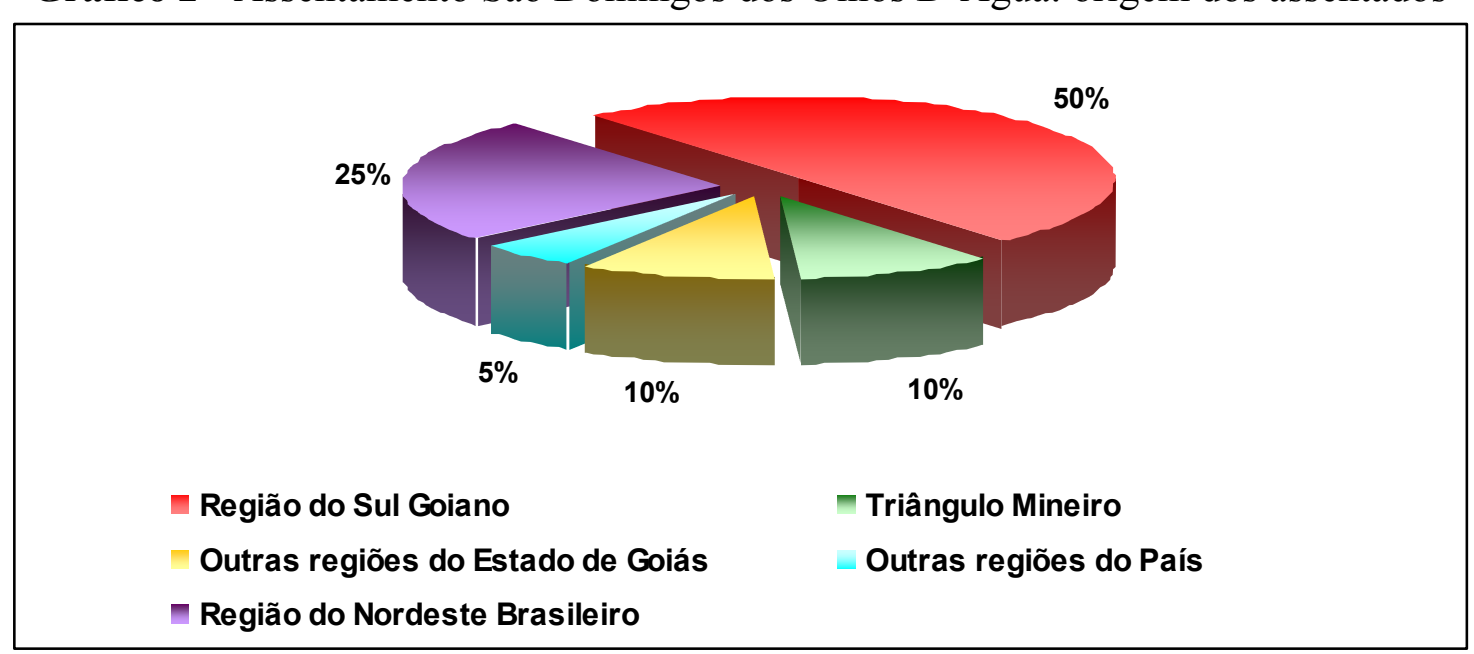

Fonte: Pontes (2014).

A maioria dessas pessoas residia na cidade, mas estava ociosa, em parte por não ter qualificação para ocupar os empregos existentes nas cidades. Assim, se é certa a insuficiência de qualificação dessa mão de obra obrigada a migrar para a cidade, é mais certo ainda que o capital sofra de uma crise estrutural permanente que produz excluídos e os culpa, a eles próprios, por essa sua condição. Esses trabalhadores são marginalizados e segregados pelo capital no campo e na cidade, o mesmo capital que transfere a eles a responsabilidade de estarem vivendo parcialmente e não possuírem qualificação profissional.

Morar na cidade, para esses trabalhadores, era conviver com a instabilidade permanente. Não tendo vínculos empregatícios, nem na cidade nem no campo, alguns exerciam a função de serviços braçais e trabalhavam na informalidade na cidade e, no campo, a prestação de serviços era por empreitadas ou como rendeiro/arrendatário, o que não garantia renda fixa nem estabilidade, pois apenas uma minoria encontra trabalho em época sazonal, principalmente em tempo de colheita de safras.

$\mathrm{Na}$ cidade, as condições de trabalho são precárias e incluem uma extensiva jornada de trabalho, que se inicia ao irem para os pontos de ônibus ainda de madrugada, às quatro horas da manhã, para utilizar ônibus, muitas vezes precários, de segurança duvidosa, que colocam em risco a vida deles, e a maioria viaja em pé. A jornada só termina no campo por volta das $17 \mathrm{~h} 00$. Antes da fiscalização das leis trabalhistas e 
eleitorais mais rigorosas ${ }^{3}$, era comum candidatos a cargos políticos servirem aos trabalhadores café da manhã, em troca de futuros votos.

Quando esses sujeitos optaram por entrar na luta pela terra, o objetivo era sair da condição de segregação social, deixar de ser trabalhador da terra para trabalhar e cultivar a sua própria terra, produzir para viver com dignidade: territorializar-se e propiciar melhores condições socioeconômicas para suas famílias. O depoimento a seguir demonstra a condição do trabalhador da terra sem terra para trabalhar.

Nós vivia na terra dos outros, quando a gente pensava que estava empregado, o dono da fazenda vinha e mandava a gente embora. E aí saímos à procura de outro patrão, não era fácil. A gente às vezes não tinha nem o que comer, era muito dificil, o sofrimento era grande. E foi esse sofrimento enorme que nos encorajou de encarar essa luta (ENTREVISTA 16, 2014).

Martins (1986) corrobora esse sentimento relatado ao afirmar que, para o capital, a terra é mercadoria, é para negócios, é lugar de exploração do trabalho de outrem, mas, para o trabalhador da terra, é meio de trabalho para a sobrevivência. O trabalho desenvolvido nos lotes é predominantemente familiar, e a maioria das pessoas ativas das famílias tem idade para trabalhar. Segundo o relato dos responsáveis pelos lotes, todos gostam do trabalho que desenvolvem, e é desse trabalho que provém a renda das famílias. Praticamente todas as famílias do assentamento comercializam alimentos por meio da Cooperativa ou da Associação e nas feiras dos centros urbanos da região.

Os tipos de produção e trabalho estão diretamente ligados à subsistência do núcleo familiar, e o excedente é comercializado. Os principais produtos alimentícios produzidos no assentamento são: leite, mandioca, frutas (principalmente mamão, manga, Goiaba, banana, maracujá), hortaliças e legumes, como beterraba, cenoura, quiabo e abóbora, além de grãos de maneira geral, dentre outros. A diversidade de gêneros alimentícios vem diminuindo porque as áreas destinadas à cultura de grãos e hortifrutigranjeiros vêm sendo ocupadas pela pastagem, mas, mesmo assim, em quase todos os lotes, os camponeses plantam suas roças para o autoconsumo. Os assentados afirmam que o aumento das pastagens é devido à constância de renda que o leite lhes proporciona. Na pesquisa de campo, foi possível notar que poucos assentados possuem ordenha mecânica; o processo de ordenha é manual e em instalações precárias. A melhoria genética do rebanho poderia aumentar a produção, conforme afirmam os 
próprios assentados.

Quanto às perspectivas da agricultura familiar, o modelo desenvolvido no assentamento tem futuro incerto, pois os descendentes (filhos e netos) são incentivados pelos pais a buscarem alternativas de trabalho qualificado nas cidades. Os pais acreditam que a cidade oferece um ambiente mais perigoso, mas dizem que, no aglomerado urbano, com estudo, um adulto tem mais condição de defender o seu sustento. Esse tipo de afirmação demonstra que, apesar da luta por acesso a terra, os assentados não percebem nas atividades da agricultura familiar perspectivas para seus familiares.

Foi ainda mensurado que apenas $20 \%$ dos parceleiros prestam serviços fora de seu lote, como pedreiros, eletricistas, carpinteiros e operadores de máquinas agrícolas. Esses parceleiros prestam serviços exclusivamente para os demais membros do assentamento e apresentam um custo mais atraente em comparação aos prestadores de serviços da cidade de Morrinhos. Os demais parceleiros, cerca de 80\%, concentram-se em atividades pertinentes à lida cotidiana no lote, sob a justificativa da impossibilidade de conciliar trabalho na parcela com outras ocupações.

Quanto ao preconceito em relação aos assentados, é uma incógnita, pois as respostas estão muito associadas à percepção dos entrevistados, percebendo-se equivalência entre aqueles que relatam a inexistência de preconceito e os relatos que descrevem a sua existência. Uns afirmaram não haver preconceito nas escolas, no comércio, lojas, bancos e demais órgãos públicos, já outros afirmam perceber olhares e descasos em algumas das relações necessárias no contexto externo ao assentamento. Diante do relato dos entrevistados, percebe-se que o preconceito e os conflitos, na atualidade, são mais internos que externos. Como a comunidade está em franco desenvolvimento, uns parceleiros conseguem adequar-se às normas, sejam elas ambientais, sanitárias ou até mesmo comunitárias, outros não, daí surgem os conflitos. A questão da alteridade, portanto, é vista com a complexidade das relações sociais, pois foi detectado que a sociabilidade é diferente entre o indivíduo em conjunto e a unidade.

Os assentados conseguem produzir não apenas para consumo próprio, mas também para a comercialização. Contudo, há a dependência das condições de mercado. Segundo Paulino (2006), essa é uma especificidade da classe camponesa que controla, ao mesmo tempo, a força de trabalho e os meios de produção. Para o autor, o camponês comercializa sua produção em condição desvantajosa por depender das condições de 
mercado além do seu controle, o que implica, frequentemente, remuneração inferior ao valor do trabalho. Nesse processo, os agentes do mercado apropriam-se da renda gerada pelo camponês. Desse modo, a dependência do camponês das relações de mercado implica uma integração subordinada, apesar da sua condição distinta em comparação ao trabalhador assalariado.

Outra situação favorável ao mercado, quando ocorre a comercialização da produção camponesa, é que, diferentemente do trabalhador individual que, ao vender sua força de trabalho gera custos para o capitalista que, na verdade, são direitos trabalhistas, o camponês não gera esses custos. $\mathrm{O}$ preço de seus produtos é o mercado que estabelece. Por isso, segundo Paulino (2006), o camponês, o pequeno produtor, torna-se parceiro preferencial dos capitalistas, principalmente da agroindústria.

Para Piraux et al. (2012), a atual política de produzir para o mercado está inviabilizando o produtor familiar e tornando-se um desafio imensurável, sobretudo para pequenos sitiantes e assentados que não têm acesso ao crédito e aos recursos técnico-agrícolas que incrementam a produtividade. Na visão do autor, que se baseia no mix de produção e produtividade de agricultores familiares em Goiás em situação de assentamento, é interessante estudar os mecanismos da prática produtiva dessa classe, particularmente num viés de sustentabilidade, observando se o sistema produtivo está rompendo os paradigmas e tendências macroeconômicas de uma atividade voltada para o agribusiness, ou está evidenciando a manutenção de usos, costumes e saberes produtivos locais, ou até trabalhando para a prática das duas perspectivas: produzir para o mercado, sem agressão à cultura de seus agentes, e não contribuir para degradação do meio ambiente.

O exame das condições atuais dos trabalhadores rurais e das narrativas coletadas durante a pesquisa denota as contradições relacionadas à instalação e consolidação do assentamento. A realidade local indica a possibilidade de se promover desenvolvimento local no âmbito rural que os movimentos sociais e a Comissão Pastoral da Terra defendem. Para Gliessman (2000), a viabilização da agricultura familiar é um mecanismo de transformação estrutural que proporciona qualidade de vida pela articulação sistêmica e consciente dos trabalhadores rurais. Entretanto, esse cenário é perpassado por conflitos quanto à luta pela posse e uso da terra, conflitos ligados à questão do trabalho, conflitos ligados à luta pela cidadania, conflitos ligados 
às políticas públicas de crédito rural e de subsídios governamentais. Esses conflitos localizam-se e se materializam no território.

Assim, a formação de um novo espaço rural é colocada como um novo paradoxo para o modelo campesino de produção, seja para os assentados de um modo em geral, seja para os demais pequenos produtores excluídos do modelo predominante, que é a agricultura empresarial. Os trabalhadores rurais não desejam a mera distribuição de terras e pequenos lotes, fato que apenas os leva a continuar barateando a mão de obra para o sistema capitalista (SILVA, 1981). Eles almejam uma estrutura política e social no campo que não apenas fortaleça o poder dos grandes proprietários de terras.

\section{Considerações finais}

O Brasil possui uma das maiores quantidades de terras agricultáveis, e também uma das mais altas taxas de concentração de terra, que se tornou uma das mercadorias mais cobiçadas do sistema capitalista e, por isso, os trabalhadores foram excluídos dela e das possibilidades de ter acesso a ela, a não ser pela luta. As políticas agrárias do país privilegiaram os latifundiários ao longo da história. O pequeno agricultor e os trabalhadores da terra, ao serem excluídos e expulsos, organizaram formas de resistência e de luta, manifestadas com os vários movimentos sociais que marcaram a trajetória das políticas agrárias do país.

Esses movimentos sociais, presentes em todas as regiões e com diferentes características quanto à forma de organizar a luta da terra, têm conseguido muitas vitórias, mas a situação ainda está distante de ser a ideal. A distribuição de terras pelo governo não é fruto de planejamento, de uma efetiva política de desconcentração fundiária, mas sim, da luta dos trabalhadores sem terra e de algumas entidades que lutam por essa causa.

Na região do sul-goiano, no município de Morrinhos (GO), depois de seis anos de luta ocorreu a primeira distribuição da terra de acordo com a lei, que estabelece que toda propriedade rural tem uma função social a cumprir, ser produtiva. Se for improdutiva, pode ser requisitada pelo INCRA para ser distribuída àqueles que, de fato, vão utilizá-la para dela viver.

Na pesquisa sobre o processo de ocupação e posse do território no PA São Domingos foi detectado que, quando o governo distribuiu terras por iniciativa própria, 
foi para abrir novas fronteiras agrícolas que, de certa forma, ampliaram mais ainda o capital. Quem mais se beneficiou dessas ações foram os latifundiários.

Os trabalhadores rurais sem terra que lutaram pela fazenda São Domingos dos Olhos D’Água, no município de Morrinhos (GO), conquistaram a terra. Eles eram da terra, são da terra e estão na terra. Resistência, existência, permanência e luta são palavras indissociáveis da reforma agrária, que, apesar de ter favorecido as 86 famílias em Morrinhos e tantas outras pelo Brasil, ainda é insuficiente. Ao se investigarem as relações de poder estabelecidas entre os trabalhadores rurais e os demais agentes sociais envolvidos no processo de ocupação e posse do território estudado, foi possível entender a ocupação territorial iniciada com os projetos de assentamentos rurais como um processo além da simples luta pela terra, pois constatou-se na pesquisa que a promoção de uma ocupação fomenta, com a diversidade de relações comunitárias, uma filosofia de vida nos assentados. Esse advento leva os participantes à internalização de uma identidade enquanto cidadãos e sujeitos políticos com direito à inclusão. Desse advento surgem conflitos entre os próprios trabalhadores rurais e também entre esses e os demais agentes envolvidos no processo de ocupação e posse do território.

$\mathrm{O}$ estudo demonstra a impossibilidade de se promover o desenvolvimento sem estimular o protagonismo local e, ao promover esse protagonismo, delega-se um empoderamento a determinados agentes, surgindo, assim, os conflitos. Os assentamentos rurais, portanto, criam paradigmas que vão além do processo políticosocial, pois apenas o ato institucional de sua criação não encerra a questão. A formalização encerra o processo político-social com a intervenção do Estado quebrando o monopólio da terra e o conflito fundiário. Entretanto, inicia-se outro com a constituição de um novo território, onde emerge uma organização social, política e econômica balizada por relações de consumo, poder e conflitos quanto ao gerenciamento do assentamento e sua estruturação interna e relações com os demais atores e instituições sociais.

A pesquisa revelou que os assentamentos rurais cumprem um papel fundamental na dinamização da economia dos municípios onde estão localizados. Revelou também que esse impacto positivo não está limitado aos municípios pequenos e com a economia estagnada, mas também aos municípios maiores e com um setor econômico mais 
dinâmico e diversificado, como é o caso de Morrinhos (GO), onde está situado o assentamento estudado.

A simples implantação do projeto de assentamento condiciona um volume de crédito a ser disponibilizado aos assentados, bem como o volume de demanda de produtos e serviços que vão ser gerados no comércio local, o que fomenta o desenvolvimento local, com alocação dos recursos para incrementar atividades nos lotes por meio de programas de apoio à agricultura familiar.

Ao buscar compreender a formação do território relacionada ao processo social de desenvolvimento local mediante o estudo dos conflitos ocorridos no processo de ocupação, posse e permanência na terra pelos trabalhadores rurais do Projeto de Assentamento São Domingos dos Olhos D'água, ficou evidenciado, diante das contribuições teóricas e conceituais discutidas neste estudo, que os assentamentos são um espaço fomentador do desenvolvimento. Com suas associações e cooperativas, os assentados podem favorecer a promoção do dinamismo econômico e a melhoria da qualidade de vida de seus membros e da localidade de inserção. Contudo, esse processo é perpassado por conflitos relativos à estruturação do assentamento e da relação constituída com a comunidade externa.

\section{Notas}

1. Oral é apresentada por meio da entrevista, e a escrita pela análise dos documentos oficiais, como atas e ocorrências policiais, por exemplo (FRANCO, 2003).

2. A denominação corresponde ao trabalhador rural assentado em cada parcela que compõe o assentamento.

3. A legislação relativa atuação dos candidatos a cargos eletivos torna-se mais rigorosa a partir de 1997, o que impactou na relação estabelecida com os eleitores (BRASIL, 1997).

\section{Referências}

AMORIM, G. G.; VIEIRA, E. T.; SANTOS, M. J. Articulação de gestão pública entre as esferas municipal e federal: um estudo do desenvolvimento local em Jaú do Tocantins. Sociedade e Desenvolvimento Rural, v. 8, p. 26-39, 2014.

ARRIGHI, G. A ilusão do desenvolvimento. $3^{a}$ ed. Petrópolis: Vozes, 1997. BARDIN, L. Análise de conteúdos. Trad. Luís Antero Reto e Augusto Pinheiro. Lisboa: Edições 70, 1994.

BOURDIEU, P. O poder simbólico. $8^{a}$ ed. Rio de Janeiro: Bertrand Brasil, 2004. 
BRASIL. Lei $\mathbf{n}^{\mathbf{0}}$ 9.504, de 30 de setembro de 1997. Dispõe estabelece normas para as eleições. Senado, 1997.

BUARQUE, S. C. e BEZERRA, L. Projeto de desenvolvimento municipal sustentável - bases referenciais. Projeto Áridas (mimeo), dezembro de 1994.

CARNIELLO, M. F.; SANTOS, M. J. dos. Comunicação e desenvolvimento regional. Taubaté: Revista Brasileira de Gestão e Desenvolvimento Regional, v. 9, n. 2, p.325345, mai-ago/2013.

CARNIELLO, M. F.; SANTOS, M. J. dos. Relações entre Acesso à Informação e Formação de Capital Social em âmbito regional: uma Proposta Metodológica. Intercom - Sociedade Brasileira de Estudos Interdisciplinares da Comunicação. XXXIV Congresso Brasileiro de Ciências da Comunicação - Recife - 2 a 6 de setembro de 2011.

CASTELS, M e BORJA, J. As cidades como atores políticos. Novos estudos CEBRAP - Dossiê Cidades, n. 45, julho de 1996.

CPT. Boletim da Comissão Pastoral da Terra: Notícias da Terra e da Água. Ano 24 - Goiânia, Goiás. Edição no ${ }^{\circ} 18$ de 2011 - De 14 a 28 de dezembro 2011.

COSTA, L. F. da; ÍTAVO, L. C. V.; SOARES, C. M.; CEREDA, M. P.; MACIEL, J. de C.; ÍTAVO, C. C. B. F. Democracia e desenvolvimento local em assentamentos rurais. Interações (Campo Grande), Campo Grande, v. 11, n. 2, Dec. 2010. Disponível em: <http://www.scielo.br/scielo.php?script=sci_arttext \&pid=S15180122010000200005 \&lng =en\&nrm=iso>. Acesso em: 24 set. 2013.

FERNANDES, B. M. MST: formação e territorialização. São Paulo: Hucitec, 1996.

FERNANDES, B. M. Que Reforma Agrária? In A Questão Agrária na Virada do Século. Vol. II - Mesas Redondas. XIV Encontro Nacional de Geografia Agrária. Presidente Prudente, 1998.

FRANCO, M. L. P. B. Análise de conteúdo. Brasília: Plano Editora, 2003.

FURTADO, R., FURTADO, E. A intervenção participativa dos atores (INPA) - uma metodologia de capacitação para o desenvolvimento local sustentável. Brasília: Instituto Interamericano de Cooperação para a Agricultura (IICA), 2000.

GLIESSMAN, S. R. Agroecologia: processos ecológicos em agricultura sustentável. Porto Alegre: UFRGS, 2000.

HAESBAERT, R. O mito da desterritorialização: do fim dos territórios à multiterritorialidade. Rio de Janeiro: Bertrand Brasil, 2004.

HEIDRICH, Á. L. Fundamentos da formação do território moderno. In: Boletim Gaúcho de Geografia. Porto Alegre: Associação dos Geógrafos Brasileiros; Santa Cruz do Sul: Editora da UNISC, no. 23, 1998, pp. 9-22.

HERNÁNDEZ S.; COLLADO, F.; BAPTISTA, P. Metodología de la Investigación. México, Df: McGRaw-Hill, 1991. 
LEITE, S. P. Assentamento rural. In: Dicionário da Educação do Campo. CALDART, R. S. (org.). Rio de Janeiro, São Paulo: Escola Politécnica de Saúde Joaquim Venâncio, Expressão Popular, 2012.

MAIA, G. S.; KHAN, A. S.; SOUSA, E. P. de. Avaliação do impacto do Programa de Reforma Agrária Federal no Ceará: um estudo de caso. Economia Aplicada, Ribeirão Preto, v. 17, n. 3, 2013.

MARTINS, J. S. Os camponeses a política no Brasil: as lutas sociais no campo e o seu lugar no processo político. $3^{\text {a }}$ ed. Petrópolis RJ: Vozes, 1986.

OLIVEIRA, A. U. de. A agricultura camponesa no Brasil. $3^{a}$ ed. São Paulo: Contexto, 1997.

PAULINO, E. T. Por uma geografia dos camponeses. São Paulo: Editora UNESP, 2006.

PIRAUX, M., L. S.; PAULO D. e GHISLAINE D.. Transição agroecológica e inovação socioterritorial. Estudos Sociedade e Agricultura, abril de 2012.

PONTES, A. E. Ocupação territorial e conflitos: o caso do assentamento São Domingos dos Olhos D`Água. Dissertação de Mestrado. Taubaté: Universidade de Taubaté, 2014.

PUTNAM, R. D. Comunidade e democracia: a experiência da Itália moderna. Trad. Luiz Alberto Monjardim. $5^{a}$ ed. Rio de Janeiro: FGV, 2006.

RAFFESTIN, C. Por uma Geografia do Poder. São Paulo: Ática, 1993.

RICHARDSON, R. J. Pesquisa Social: métodos e técnicas. São Paulo: Atlas, 1999.

SANTOS, B. de S.; MENESES, M. P. (Orgs.) Epistemologias do Sul. São. Paulo: Editora Cortez,2010.

SANTOS, M. A natureza do Espaço: técnica e tempo, razão e emoção. São Paulo: Hucitec, 1996.

SEN, A. Desenvolvimento como liberdade. São Paulo: Companhia das Letras, 2000.

SILVA, C. M. R. B. A Cidade de Morrinhos uma Abordagem Geográfica. Goiânia: GRAFSET - Gráfica e Editora, 2006.

SILVA, J. G. O que é questão agrária, $3^{a}$ ed. São Paulo: Brasiliense, 1981.

SOUZA, M. J. L. O Território: Sobre Espaço e Poder, Autonomia e Desenvolvimento. In:CASTRO, et. al.(Orgs.).Geografia: Conceitos e Temas, Rio de Janeiro:Bertrand Brasil,1995.

STÉDILE, J. P. A Questão Agrária e o Socialismo. In: ESTEDLE, João Pedro et al. (Orgs.). A Questão Agrária Hoje. Porto Alegre; Universidade / UFRGS, 2002.

VAZ, J. P. Desigualdade Social e Produtividade Social no Brasil de 1960-2000. Tese de Doutorado em História Social - Universidade de São Paulo: São Paulo, 2005. 
VEIGA, J. E. da. A face territorial do desenvolvimento. Revista Internacional de Desenvolvimento Local, vol. 3, n. 5, p. 5-19, 2002.

VIEIRA, E. T.; SANTOS, M. J. As ferramentas quantitativas e qualitativas na análise histórica do desenvolvimento regional: o Vale do Paraíba de 1970-2000. Dialogos (Maringá), v. 17, p. 279-307, 2013.

VIEIRA, E. T.; SANTOS, M. J. dos. Desenvolvimento econômico regional: uma revisão histórica e teórica. Revista Brasileira de Gestão e Desenvolvimento Regional, Taubaté, SP, v. 8, n. 2, p. 344-369, mai-ago/2012.

YIN, R. K. Estudo de caso: planejamento e métodos. $3^{\text {a }}$ ed. Porto Alegre: Bookman, 2002. 